\title{
Failure of a steel boiler chimney caused by corrosion of the structural shell plate
}

\author{
Zdzislaw Pisarek ${ }^{1, *}$ \\ ${ }^{1}$ Rzeszow University of Technology, Dept. of Building Structures, 35-084 Rzeszow, Poland
}

\begin{abstract}
The article presents issues concerning the corrosion of sheets of the guyed steel chimney with boiler house in an industrial plant. The subject of considerations is a steel chimney with a height of $46.5 \mathrm{~m}$ and a diameter of $1.25 \mathrm{~m}$. The chimney was used for seventeen years and did not show any significant corrosion losses. After the change of the way of usage and the fuel used for feeding boilers, the corrosion rate has dramatically increased. The paper presents issues concerning corrosion types and mechanisms of corrosion degradation of the steel. The reasons for the increase of corrosion velocity within the chimney base were given. The method of chimney renovation and the results of this renovation, detailing the order of works is presented too. Attention was also paid to the proper maintenance of construction works, as periodic inspections themselves may be insufficient to ensure safe operation.
\end{abstract}

\section{Introduction}

Chimneys are an inseparable part of the landscape of industrial plants. They are used to remove to the atmosphere flue gas from power plant boilers and fumes from production processes. One of the used types of chimney are steel chimneys. Widespread use of the steel chimneys is due to the relatively low weight, ease of production and speed of assembly. The disadvantages of steel chimneys are their vulnerable to the corrosion and excessive vibrations caused by the wind, as well as the influence of thermal interactions, especially in chimneys which discharge hot gases. The effects of corrosion, temperature and vibrations caused by the impact of wind on chimney structure elements and their connections significantly affect the durability and failure frequency of steel chimneys. These features must be taken into account in the design process, decisions on construction and material solutions, in computational procedures, and during operation through appropriately frequent technical inspections.

Particularly low corrosion durability exhibits a single-wall steel chimneys without the inner lining system. This is due to particularly difficult operating conditions and a low relation of the costs of producing a new chimney to the costs of protection and repair, where the only protection is allowance for corrosion. Defects of the thickness of the structural shell plates occur in places where aggressive corrosive agents are present. These places in the chimney's interior are the area of the inlet (high temperature) or the area around the cope

\footnotetext{
${ }^{*}$ Corresponding author: pisarzdz@prz.edu.pl
} 
hood, where, together with the water, highly sulphated flue gas creates strong acids that cause accelerated corrosion of the chimney structural plates. Also, the connection points - bolts flange contacts and welds between the structural shell plates are potential sources of corrosion. Corrosion of external chimney surfaces caused by atmospheric phenomena usually has little effect on the durability of the object. Damage to the chimney structural shell during its operation usually arises due to several reasons at the same time. In order to maintain the chimney durability anticipated in the project, one must absolutely control the ignition of the flue gas aggressiveness and temperature in the pipe, in order to prevent the state from before the emergency chimney. Caring for the chimney's operation parameters and frequent inspections of the technical condition increases its durability.

\section{Description of the object}

The steel chimney subjected to the study was made according to the "Construction project of typical steel guyed chimneys for heating plants - KO-1250/45. H=45,0 m; D=1,25 m.”- made by the Main Research and Development Centre "BISTYP" Warsaw [1]. The chimney is located near the boiler house in the industrial plant. The guyed chimney has a height of $46.5 \mathrm{~m}$ and an external diameter of $1250 \mathrm{~mm}$ (Fig. 1). The chimney shaft is held by a rope at a level of $28.5 \mathrm{~m}$ through three cables made of $6 \times 19+$ A ropes with a diameter of $\phi=40 \mathrm{~mm}$ with a nominal breaking force of $1080 \mathrm{kN}$.

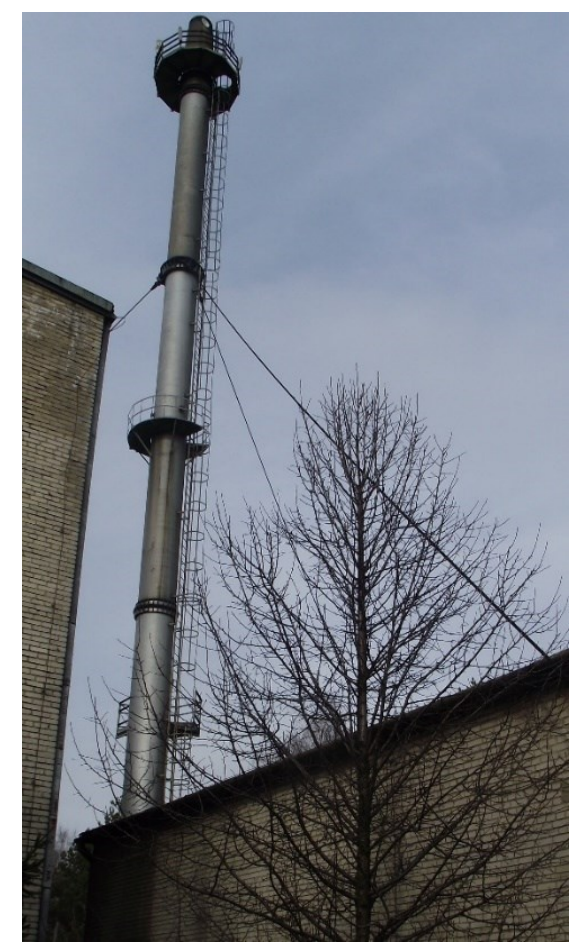

Fig. 1. General view of the chimney.

The chimney was designed as a self-supporting round wire carrying the wind load. The elements of the chimney shaft have different lengths; i.e. segment 1 - 15 m; segment 2 - 13.5 m; segment $3-12.5 \mathrm{~m}$; and segment $4-5 \mathrm{~m}$. The segments are connected to each other by means of a flanged bolted joint with $36 \mathrm{M} 20$ bolts, class 4.8 . Each segment of the chimney consists of sheet metal with a length of $1.5 \mathrm{~m}$ welded together in the factory in an automatic 
manner. At the top, the chimney shaft is equipped with a cope hood. The basic plate of the chimney connected to the reinforced concrete foundation with $16 \mathrm{M} 30$ anchor bolts. The chimney has three steel platforms at level of $11.3 \mathrm{~m}, 20.90 \mathrm{~m}$, and $41.1 \mathrm{~m}$, wherein the platform at elevation of $11.3 \mathrm{~m}$ (at the inspection openings) is an incomplete bridge. The waste gas pipeline is connected to flue inlet of about $3 \mathrm{~m}$ from the ground level. The chimney is equipped with a ladder with a protective bow.

In 2010, antennas of mobile telephony were added to the gallery of the upper chimney (Fig. 2). The chimney supports three coal-fired boilers and is used continuously, with only one boiler operating outside the heating period.

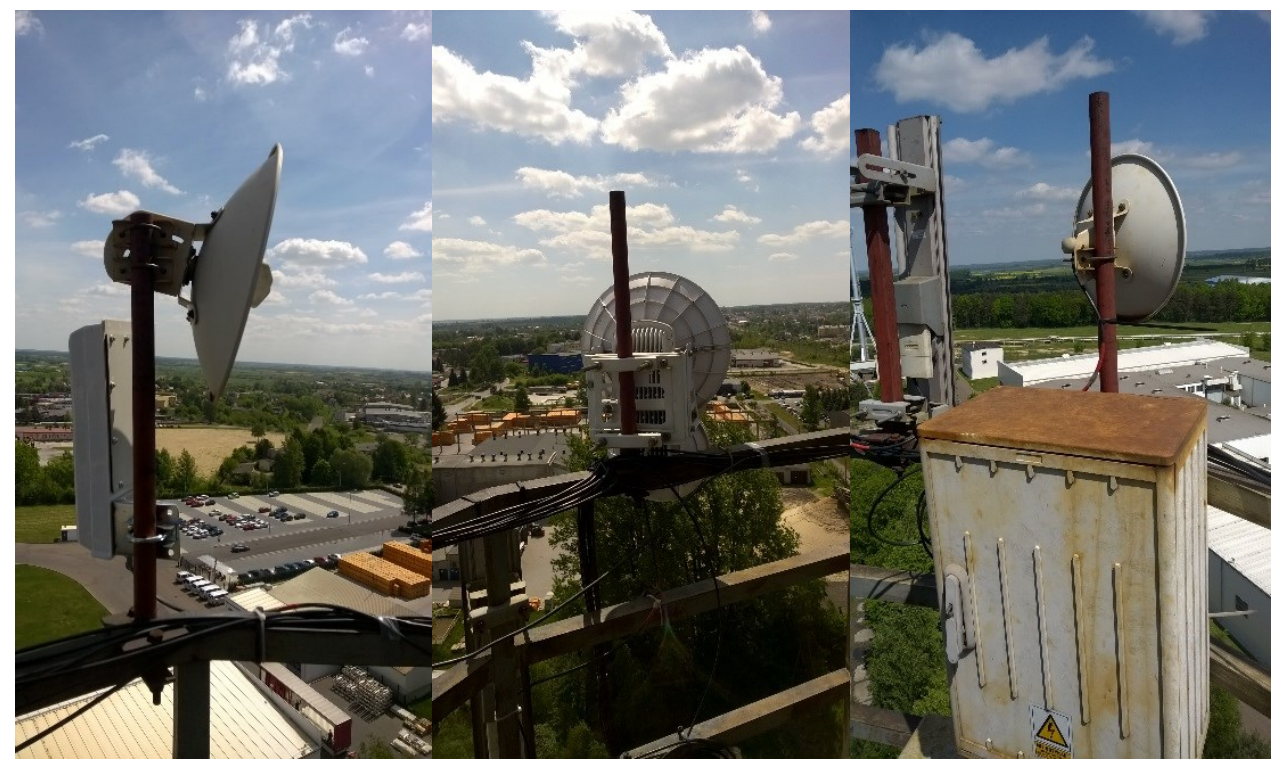

Fig. 2. Mobile telephony antennas on the upper chimney gallery - additional load.

\section{Controls of technical condition}

The chimney has been in operation since 1992. The first technical inspection of the condition of the chimney was in 1996. Corrosion defects of the reinforced concrete foundations were then found, which after the previous cleaning were supplemented with new concrete.

Chimney shaft condition checks were carried out in 2006 and 2009. These inspections assessed that the technical condition of the chimney shaft was satisfactory. There were small dents of the chimney structural plates, but the deflection does not exceed the wall thickness of the chimney shaft. The condition of the coatings on the chimney flock was satisfactory. The anchorages of the guys were in good condition, no significant signs of corrosion were noticed. The condition of the ropes themselves was good, although few cracks in the wires were noticed. The condition of the working platforms and the ladder was sufficient. Their durability was preserved, although the bridge level of $41.1 \mathrm{~m}$ had bent metal sheets, traces of corrosion, poorly made welds and other defects.

\section{Checks on the thickness of the structural shell plates}

During the inspection of the technical condition, measurements of the thickness of the chimney shaft plates were also carried out using an ultrasonic thickness gauge. Thickness measurements were made in places most exposed to corrosive influences, 
i.e. in frontal joints connecting individual sheets of chimney shaft elements, on average every $1.5 \mathrm{~m}$, at the contact points of assembly segments, and near the chimney shaft support area and at the chimney support on the foundation. The measurement results from 2006 and 2009 are shown in Fig. 3.

Table 1 shows the calculated average values of the thickness of individual segments of the chimney shaft measured in 2006 and 2009, and the size of the average corrosion loss within one year. To calculate the corrosion progress, the period from the beginning of use was assumed, taking the thickness of the chimney jacket sheet as nominal.

Table 1. Checks on the thickness of the structural shell plates.

\begin{tabular}{|c|c|c|c|c|c|c|}
\hline Segment & $\begin{array}{c}\text { Average plate } \\
\text { thickness 2006 } \\
{[\mathbf{m m}]}\end{array}$ & $\begin{array}{c}\text { Standard } \\
\text { deviation 2006r. } \\
{[\mathbf{m m}]}\end{array}$ & $\begin{array}{c}\text { Corrosion } \\
\text { progress } \\
{[\mathbf{m m} / \text { year }]}\end{array}$ & $\begin{array}{c}\text { Average plate } \\
\text { thickness 2009 } \\
{[\mathbf{m m}]}\end{array}$ & $\begin{array}{c}\text { Standard } \\
\text { deviation 2009r. } \\
{[\mathbf{m m}]}\end{array}$ & $\begin{array}{c}\text { Corrosion } \\
\text { progress } \\
{[\mathbf{m m} / \mathbf{y e a r}]}\end{array}$ \\
\hline S-1 & 8.81 & 0.52 & 0.085 & 8.50 & 0.69 & 0.103 \\
\hline S-2 & 7.93 & 0.36 & 0.148 & 7.61 & 0.36 & 0.107 \\
\hline S-3 & 7.34 & 0.71 & 0.190 & 7.00 & 0.44 & 0.113 \\
\hline S-4 & 6.67 & 0.56 & 0.238 & 5.79 & 0.69 & 0.293 \\
\hline
\end{tabular}

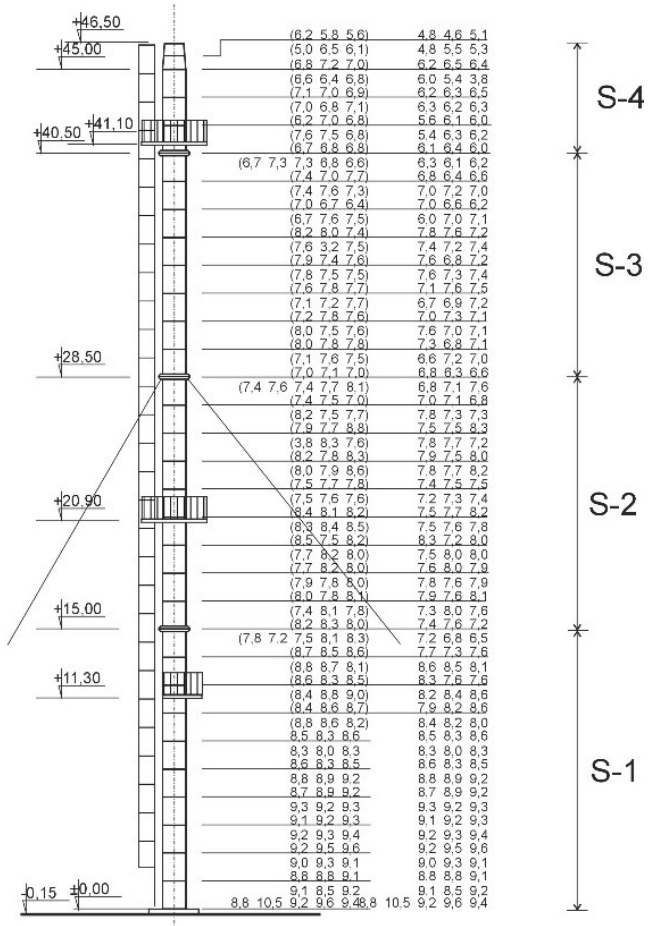

Fig. 3. Inventory drawing of the chimney.

The technical documentation recommended making the chimney shaft of the 1H18N9T stainless steel with a thickness of $7 \mathrm{~mm}$, permitting the execution of the shank of St3S standard structural steel after increasing the thickness to $10 \mathrm{~mm}$, which took place in the discussed case. To calculate the corrosion progress, the period from the beginning of use was assumed, taking the thickness of the chimney jacket sheet as nominal. The measured thickness of the chimney flute plates ranged from $10.5-3.2 \mathrm{~mm}$ and is different at 
the chimney height depending on the segment. The maximum corrosion rate occurred in the S-4 segment. This is in line with the assumptions, because the upper segments are usually the most corrosive because of the condensation of the cooled gases. In the S-3 segment, the thickness of the $3.2 \mathrm{~mm}$ sheet was scored. Perhaps it was only a measurement error, but you should pay attention to this place during the next measurements.

\section{Checking calculations}

The verification calculations were carried out on the basis of the Standard [2]. The wind force combination was adopted according to [3] for the $1^{\text {st }}$ load zone. The chimney's own vibration period was $T=0.61 \mathrm{~s}$. Maximum wind load on the top of the chimney $p_{\mathrm{k}}=1.43 \mathrm{kN} / \mathrm{m}$. Maximum stresses occurred in the place of support of the chimney on the foundation and amounted to $73.2 \mathrm{MPa}$. In the place of supporting the chimney shaft with guys at the height of $28.50 \mathrm{~m}$, the stresses amounted to $69.47 \mathrm{MPa}$. The maximum Karman vortex load causes a large number of cycles with low stress variation $\Delta \sigma=29.64 \mathrm{MPa}$. The maximum deflection of the end of the chimney from the wind load is $43.95 \mathrm{~cm}$, which is lower than the permissible value. In general, there was no indication of chimney failure in the period until the next inspection.

\section{Corrosion of the chimney structural shell plate}

During the inspection of the chimney after the winter period in 2014, the perforation of the chimney structural shell plates was noticed. The damage took place about $40 \mathrm{~cm}$ above the foundation of the chimney (Fig. 4). The damage was from the south side on the opposite side in relation to the anchorage of the guy. In the place of damage, it was noticed that the water was present with dust, soot and slag falling off the exhaust waste gases (Fig. 5). The stagnation of water and condensation was caused by clogging of the drainage conduit that was in the foundation.

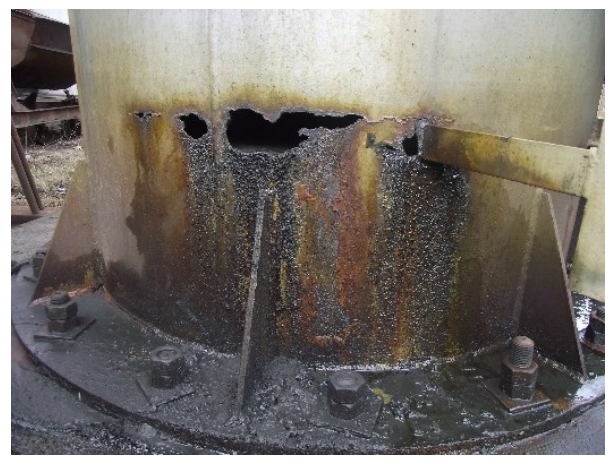

Fig. 4. Corrosion perforation of chimney sheets.

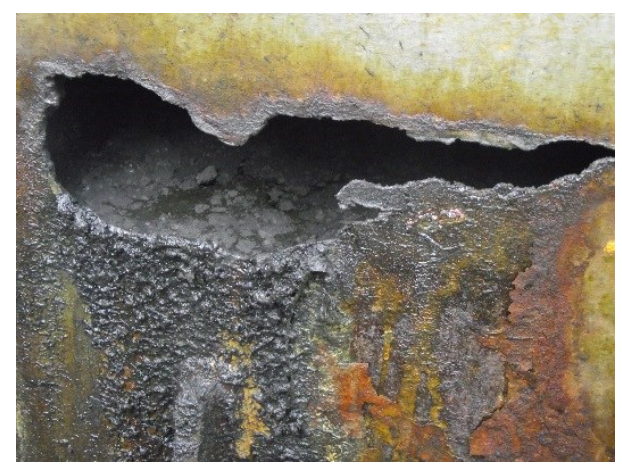

Fig. 5. Water in the interior of the chimney.

The phenomenon of soot deposition did not occur in previous periods. After an interview with the user, it turned out that the heating fuel supplier has recently changed. During combustion, this coal produced much more slag and dust transferred from the exhaust. The way of servicing boilers has also changed. Due to interruptions in the plant's operation, the boilers were turned off and the chimney was cooled down. This resulted in water coming from the precipitation in the chimney. Despite these unfavorable conditions, it was difficult to assume that the progress of corrosion would be so great. The measurements of the chimney 
structural shell plate thickness (Fig. 6) showed an adequate corrosion reserve at a specified corrosion rate of $0.103 \mathrm{~mm} /$ year.

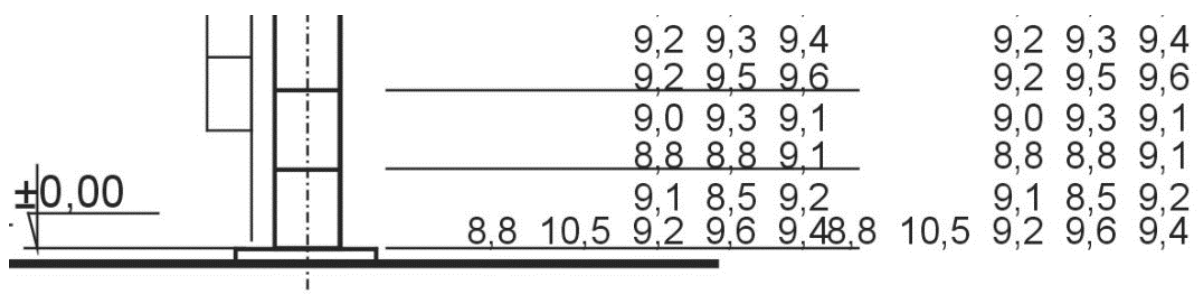

Fig. 6. The measurements of the chimney structural shell plate thickness.

\section{Causes of corrosion}

The following basic types of corrosion can be distinguished [4]:

- general corrosion (steady),

- intergranular corrosion,

- pitting corrosion (pitting),

- selective corrosion,

- corrosion cracking,

- hydrogen corrosion,

- crevice corrosion,

- gas corrosion (high temperature).

General corrosion is characterized by a uniform loss of material on the surface of the element. Its cause is the reaction of metal particles with aggressive components of the environment. Materials with low resistance to corrosion in the atmosphere and in water, as well as most metal alloys in acidic environments. Corrosion products are poorly bonded to the substrate and do not constitute a protective barrier to prevent further oxidation.

Intergranular corrosion passes along grain boundaries. It is a particularly dangerous type of corrosion, because its operation is invisible, but it leads to a significant reduction in strength and plasticity of the metal. This corrosion occurs mainly in alloy steels, where micro-cells form in the interior of the grains

Pitting corrosion is local corrosion. The pits created are often invisible but progressive damage can lead to the perforation of the element. It occurs on metals in the passive state in environments containing halide ions. In the pitting corrosion process, two stages can be distinguished: the nucleation of pits on the surface of the metal and the development of pits. To initiate pitting corrosion, there must be a minimal electrochemical potential, called breakdown potential. An increase in the current density above the breakdown potential is characterized by an increase in the corrosion rate. The decrease in the current density causes repassivation, i.e. the pitting corrosion process is inhibited.

Stress, fatigue, cavitation and erosive corrosion causes damage to materials and structures due to the aggressiveness of the environment and the simultaneous action of mechanical factors. Corrosion rate depends mainly on the occurrence of microcracks in the steel structure and tensile stresses.

The reasons for the increase in the corrosion rate should be seen in the local change of the working conditions of the roof sheath. Under typical conditions, condensation of exhaust fumes contaminated with sulphur compounds in a high concentration caused general corrosion of the upper chimney segment. Due to the lack of condensate, the lower segments were not exposed to chemical corrosion. The change of fuel containing harmful substances and forming dust accelerated the corrosion process. Among the ash-forming substances, 
alkali metal sulphates and pyrosulfates have the most aggressive interaction. As a result of $\mathrm{Fe}_{2} \mathrm{O}_{3}$ iron oxide reaction from scale, $\mathrm{K}_{2} \mathrm{SO}_{4}$ sulphate or $\mathrm{K}_{2} \mathrm{~S}_{2} \mathrm{O}_{7}$ potassium metabisulfite from ash and $\mathrm{SO}_{3}$ sulphur oxide from flue gas:

$$
\mathrm{Fe}_{2} \mathrm{O}_{3}+3 \mathrm{~K}_{2} \mathrm{SO}_{4}+3 \mathrm{SO}_{3} \rightarrow 2 \mathrm{~K}_{3} \mathrm{Fe}\left(\mathrm{SO}_{4}\right)_{3}
$$

or

$$
\mathrm{Fe}_{2} \mathrm{O}_{3}+3 \mathrm{~K}_{2} \mathrm{~S}_{2} \mathrm{O}_{7} \rightarrow 2 \mathrm{~K}_{3} \mathrm{Fe}\left(\mathrm{SO}_{4}\right)_{3}
$$

These compounds accelerate the corrosion processes by acting like electrolytes. In addition, the carbon compounds in the water act as a catalyst to accelerate the reduction of oxygen in the water.

The precipitation water diluted the sulfuric acid concentration, which also caused acceleration of corrosion (Fig. 7), as well as reduced the access of air, which also increased the speed of corrosion (Fig.8) [4]. In addition, the prevailing tensile stresses from wind forces in this part of the chimney, initiated stress corrosion.

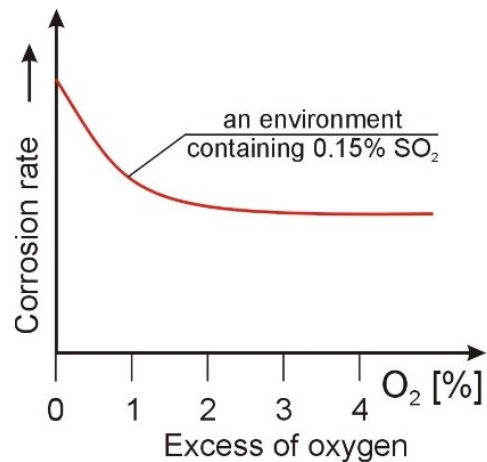

Fig. 7. Corrosion rate of low carbon steel in the atmosphere of exhaust gases.

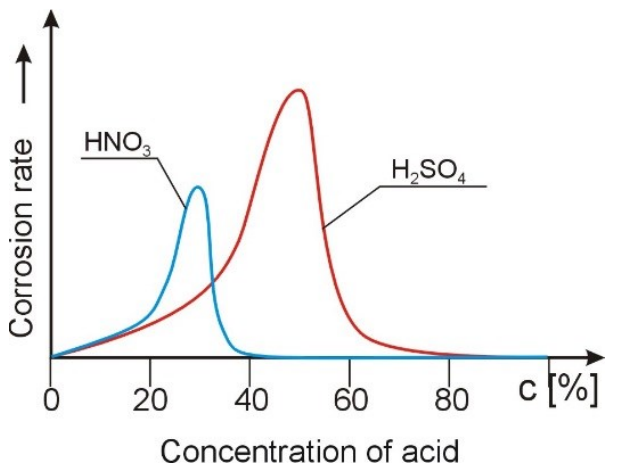

Fig. 8. Dependence of the corrosion rate of steel on the concentration of acid.

\section{Repair method}

To protect the chimney against further devastation, it was ordered to immediately repair the damaged part of the bottom of the chimney shaft. Repair of the resulting damage consisted of using an additional steel sheets on the perimeter of the chimney, which will take over the role of a heavily corroded part at the foundation. Due to ribbing and access door existing here, as well as the necessity of the best connection with the existing construction of additional sheets, it was recommended to reinforce the entire circumference of the chimney. The reinforcement was designed from a $10 \mathrm{~mm}$ thick and $1500 \mathrm{~mm}$ high sheets (Fig. 9). The width of each belt was taken so that it did not exceed $350 \mathrm{~mm}$. In each sheet before welding, holes for existing elements (stem ribs and cleanout) were cut out. Only after cutting the holes, the sheet was put on the chimney stem. After fitting, each sheet was welded to the chimney shaft and neighboring sheets in stages. In the first stage, the sheets were welded on lengths of $20 \mathrm{~cm}$, with a $20 \mathrm{~cm}$ break. In the next stage, the welds were refilled. A drain hole was left in the chimney wall (Fig.10). 


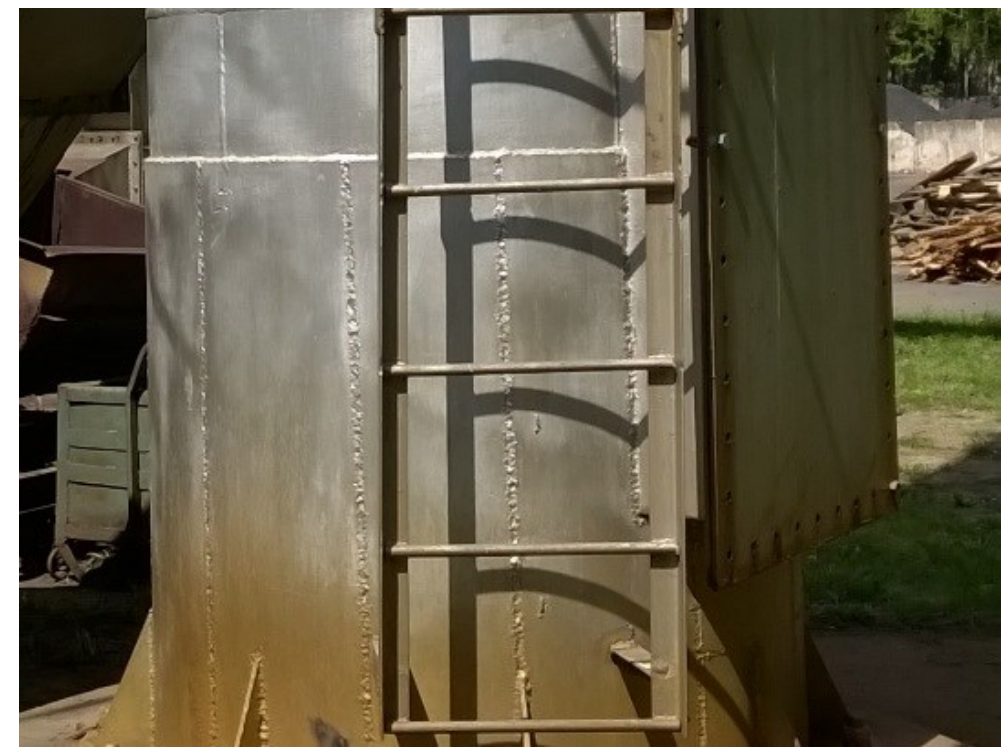

Fig. 9. Repair of the bottom part of the chimney.

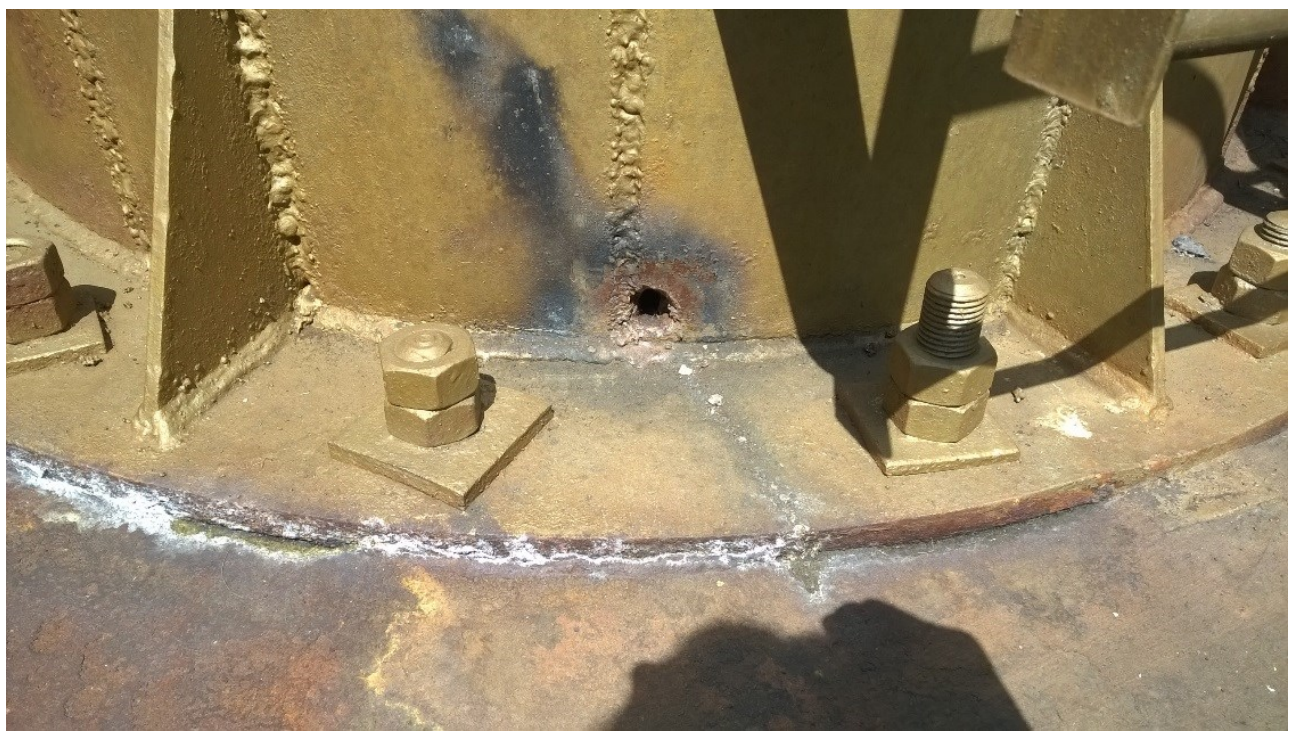

Fig. 10. The drain hole in the chimney wall.

\section{Conclusions}

Steel chimneys are objects heavily exposed to corrosive influences, therefore, special attention should be paid to these issues in the chimney design phase as well as its operation.

Adequate maintenance and ad hoc maintenance work can significantly affect the durability of the chimney. It is especially important to keep the chimney clean, as it significantly reduces its corrosion.

Burning of low-quality fuel causes not only high dustiness, smog and pollution of the environment, but also reduces the durability and time of use of the objects. 


\section{References}

1. Design project: Update of a typical steel chimney with extractors for heating plants KO-1250/45. H = 45.0 m; D = $1.25 \mathrm{~m}$. - vol. 1. Description and calculation. vol. 2. Drawings and lists. (Central Research and Design Center BISTYP, Warsaw, 1983) [in Polish].

2. PN-EN 1993-3-2 :2008: Eurocode 3 - Design of steel structures - Part 3-2: Towers, masts and chimneys - Chimneys

3. PN-EN 1991-1-4 :2008: Eurocode 1: Actions on structures - Part 1-4: General actions Wind actions

4. B. Surowska: Selected problems of corrosion and corrosion protection. (Lublin, 2002) [in Polish] 